\title{
Microwave-assisted Extraction of Flavonoids from Phyllostachys heterocycla Leaves: Optimization, Mechanism, and Antioxidant Activity in vitro
}

\author{
Jie Xu, ${ }^{\mathrm{a}}$ Jianjun Wu, ${ }^{\mathrm{a}, *}$ Juan Qi, ${ }^{\mathrm{b}}$ Juan Li, ${ }^{\mathrm{b}}$ Yongju Liu, ${ }^{\mathrm{b}}$ Zekai Miao, ${ }^{\mathrm{a}}$ Guofeng Qiu, ${ }^{\mathrm{a}}$ and \\ Wenke Jia ${ }^{\text {a }}$
}

\begin{abstract}
Flavonoids were extracted from Phyllostachys heterocycla leaves by adopting microwave-assisted extraction technology. Based on the single factor experiment and Plackett-Burman design results, the extraction process of flavonoids was further optimized using the response surface methodology. The optimum conditions were as follows: an ethanol concentration of $78.1 \%$, an extraction time of $24.9 \mathrm{~min}$, and a microwave power of $559 \mathrm{~W}$. Under these conditions, the extraction yield of flavonoids was $4.67 \%$, which was in close proximity to the predicted value $(4.70 \%)$ and higher than the extraction yield from traditional Soxhlet extraction $(3.35 \%)$. Moreover, the possible extraction mechanisms of these two extraction methods were further derived to explain why the microwaveassisted extraction of flavonoids was more efficient compared with traditional Soxhlet extraction. Ultimately, the antioxidant activities in vitro of flavonoids from Phyllostachys heterocycla leaves were evaluated via DPPH and ABTS radical scavenging assay. The flavonoids from Phyllostachys heterocycla leaves exhibited excellent antioxidant activities in vitro and Phyllostachys heterocycla leaves could be a new natural source for developing antioxidants. Overall, the findings of this research could provide a theoretical reference for the further comprehensive development and utilization of bamboo resources.
\end{abstract}

Keywords: Phyllostachys heterocycla leaves; Microwave-assisted extraction; Flavonoids; Antioxidant activity; Extraction mechanism

Contact information: a: School of Chemical Engineering and Technology, China University of Mining and Technology, Xuzhou 221116 China; b: School of Chemical Engineering, Xuzhou College of Industrial

Technology, Xuzhou 221140 China;

*Corresponding author: jjuw@163.com

\section{INTRODUCTION}

Bamboo is widely distributed throughout the world and is a perennial evergreen herb that belongs to the Gramineae family and the Bambuseae subfamily (He et al. 2014). In recent years, research on promoting the utilization of bamboo resources has been a very active field of study throughout the world. Bamboo resources have been considered as an important ingredient in traditional Asian medicine, especially in China and India (Ayurveda) (Yuan et al. 2020). Bamboo leaves are a type of forestry resource with potential utilization value worldwide. It has long history of consumption in China since it contains many secondary plant metabolites with medicinal and nutritive properties, which are related to human health (Gong et al. 2015). Bamboo leaf extract can be constituted as a light brown powder extracted from bamboo leaves and contains a large amount of 
biologically active components, which primarily include flavonoids, phenolic acids, and coumaric lactones (Gao et al. 2019).

Phyllostachys heterocycla is native to China. It grows as a thick rod, and the surface of the stalk is covered with a layer of white powder. It is one of several vital scattered bamboo species, primarily distributed in southern China (Tao et al. 2019; Yuan et al. 2021). Flavonoids are secondary plant metabolites and present in nearly all parts of bamboo, such as leaves, roots, and xylem. Flavonoids play an important role in plants growth and development. Besides, they have been related to the defense mechanism in the aerial parts (leaves and stems) of plants (Orsat and Routray 2017). Flavonoids have attracted much attention due to their beneficial health effects, including antioxidant, antifungal, antitumor, and antidiabetic effects (Fang et al. 2020; Ma et al. 2020; Li et al. 2021). Presently, flavonoids have great application potential in chemical, pharmaceutical and other industries, and the market demand for flavonoids is gradually increasing. In addition, the research on the extraction of flavonoids from vegetal materials mostly focuses on the traditional heat reflux extraction (Liu et al. 2021; Shamsuddin et al. 2021; Xia et al. 2021). This extraction process is time-consuming, laborious, and inefficient, and the quantity and quality of the flavonoids obtained from this method are not satisfactory (Proestos and Komaitis 2008; Zhang et al. 2011). Therefore, it is urgent to exploit a highefficiency extraction method with optimum parameters for achieving the maximum yield of flavonoids.

Microwave-assisted extraction is one of the advanced methods of extraction, which has been increasingly applied for the extraction of bioactive compounds. When compared with the traditional heat reflux extraction method, microwave-assisted extraction is more efficient in many cases and has many advantages, including a strong penetrating force, high selectivity, shorter extraction time, reduced solvent consumption, and a higher yield with a high quality of the targeted compound (Routray and Orsat 2012; Routray and Orsat 2014; Odabas and Koca 2021; Petrotos et al. 2021). Many reports have been published on the application of microwave-assisted extraction of secondary metabolites from plants (Zhong et al. 2016; Alara et al. 2019; Alirezalu et al. 2020; Carbone et al. 2020; Chaves et al. 2020; Yadav et al. 2020; Kaanin-Boudraa et al. 2021). Nevertheless, there is little information about the extraction of flavonoids from Phyllostachys heterocycla leaves using microwave-assisted extraction. Therefore, the primary purpose of this study was to optimize the microwave-assisted extraction of flavonoids using the response surface methodology and to elucidate the mechanism underlying microwave-assisted extraction of flavonoids from Phyllostachys heterocycla leaves and compare it with traditional Soxhlet extraction. In addition, the antioxidant activities of flavonoids were also investigated to expand its applications in the healthcare domain.

\section{EXPERIMENTAL}

\section{Materials and Chemicals}

Phyllostachys heterocycla leaves were collected from the Yibin region (Sichuan, China). These fresh leaves were rinsed with distilled water three times and dried in a vacuum oven at a temperature of $50{ }^{\circ} \mathrm{C}$ for $24 \mathrm{~h}$. Then, the leaves were ground in a domestic mixer grinder and sieved with a 60-mesh screen. Finally, the prepared samples were stored in a desiccator for subsequent experiments. The rutin, pyrogallic, salicylic acid, vitamin $\mathrm{C}$ and 1,1-diphenyl-2-picrylhydrazyl (DPPH) were purchased from Aladdin Co., while the 
aluminum nitrate, sodium nitrite, sodium hydroxide, and 2,2-azino-bis-3-ethylbenzothiazoline-6-sulfonic acid (ABTS) were procured from MacLeans Co. All chemicals were of analytical grade.

\section{Methods}

Microwave-assisted extraction

A microwave synthesis reactor (MCR-3KT, Zhengzhou Ketai Experimental Instrument Co. Ltd., Zhengzhou, China) with a maximal microwave power of $800 \mathrm{~W}$ at a frequency of $2450 \mathrm{MHz}$ was employed to extract the flavonoids. A schematic diagram of the MCR-3KT device is presented in Fig. 1. The pre-prepared Phyllostachys heterocycla leaf powder $(4 \mathrm{~g})$ was transferred into a $250 \mathrm{~mL}$ round-bottom flask containing $120 \mathrm{~mL}$ of $70 \%(\mathrm{v} / \mathrm{v})$ ethanol. Then, the flask was moved into the chamber of this device connected with condensing tubes. Next, the chamber door was closed, and programs of different microwave powers and extraction times were set. After the microwave-assisted extraction, the treated mixture was cooled to room temperature. Then, the supernatant was collected via centrifugation $(5000 \times \mathrm{g}, 15 \mathrm{~min})$ and concentrated at a temperature of $50{ }^{\circ} \mathrm{C}$ using a rotary evaporator. Finally, the concentrate was made up to a volume of $100 \mathrm{~mL}$ by adding $30 \%$ ethanol for the subsequent determination of the total flavonoid content. All experiments were investigated in triplicate.

\section{Traditional Soxhlet extraction}

A Soxhlet apparatus was used to extract the flavonoids from Phyllostachys heterocycla leaves using the following optimal conditions: the sample $(4 \mathrm{~g})$ was extracted with $120 \mathrm{~mL}$ of ethanol $(60 \%)$ for $7 \mathrm{~h}$ at an extraction temperature of $100{ }^{\circ} \mathrm{C}$ based on the preliminary orthogonal experiment $\left(4^{4}\right)$. After the Soxhlet extraction, the extracts were evaporated at a temperature of $50{ }^{\circ} \mathrm{C}$ using a rotary evaporator. Then, the extracts were transferred to brown glass bottles and stored at a temperature of $4{ }^{\circ} \mathrm{C}$ until later use. All Soxhlet extractions were performed in triplicate.

\section{Experimental Design}

Single factor experiment and Plackett-Burman design

The microwave-assisted ethanol extraction method was implemented to extract the flavonoids from Phyllostachys heterocycla leaves. The reason why this approach was chosen was that ethanol as an extraction solvent can achieve efficient recovery of flavonoids and the extraction process conforms to the principle of "green" chemistry. The extraction yield is affected by several factors, including ethanol concentration, solid to liquid ratio, temperature, and time (Su et al. 2019). Considering the multiple effects of various factors on the extraction of target compounds, it is of great importance to explore the optimal extraction conditions in terms of designing a complete extraction process. For this study, the ethanol concentration, solid to liquid ratio, extraction time, and microwave power were chosen as single factors. Then, based on the results of the single factor experiment, the Plackett-Burman design with four independent variables, i.e., ethanol concentration $\left(\mathrm{X}_{1}\right)$, solid to liquid ratio $\left(\mathrm{X}_{2}\right)$, extraction time $\left(\mathrm{X}_{3}\right)$, and microwave power $\left(\mathrm{X}_{4}\right)$, at two levels $( \pm 1)$ was applied to design 12 experimental points to explore effects of the above independent variables on the extraction yield of flavonoids from bamboo leaves. The significance of each variable was determined via a Student's t-test. 
Experimental design of the response surface methodology (RSM)

The response surface methodology (RSM) is widely applied to explore the estimated functional relationship between a response variable and design variables as well as search for the optimal conditions of factors for desirable responses. According to the preliminary results of the single factor and Plackett-Burman design experiments, the independent variables and their ranges were chosen for the further optimization. In order to obtain the optimal extracting conditions and investigate the effects of the independent variables on the flavonoid yield (Y), a Box-Behnken design with three variables, i.e., concentration of ethanol (A), extraction time (B), and microwave power (C), at three levels (Table 4) was performed using Design Expert 8.0 software (Stat-Ease, Minneapolis, MN). In addition, Y was used as the dependent variable, and its values in each trial were the average of the triplicates.

To predict the optimal extracting conditions, a second-order polynomial model concerning the relationship between the independent and response variables was established, as shown in Eq. 1,

$$
Y_{k}=a_{k 0}+\sum_{i=1}^{3} a_{k i} x_{i}+\sum_{i=1}^{3} a_{k i i} x_{i}^{2}+\sum_{i<j}^{3} a_{k i j} x_{i} x_{j}
$$

where $Y_{\mathrm{k}}$ is the response, $a_{\mathrm{k} 0}, a_{\mathrm{ki}}, a_{\mathrm{kii}}$, and $a_{\mathrm{kij}}$ are coefficients for the intercept, linear, quadratic, and interactive terms, respectively, and $x_{\mathrm{i}}, x_{\mathrm{i}}^{2}$, and $x_{\mathrm{i}} x_{\mathrm{j}}$ are the linear, quadratic, and interactive terms of the coded independent variables, respectively.

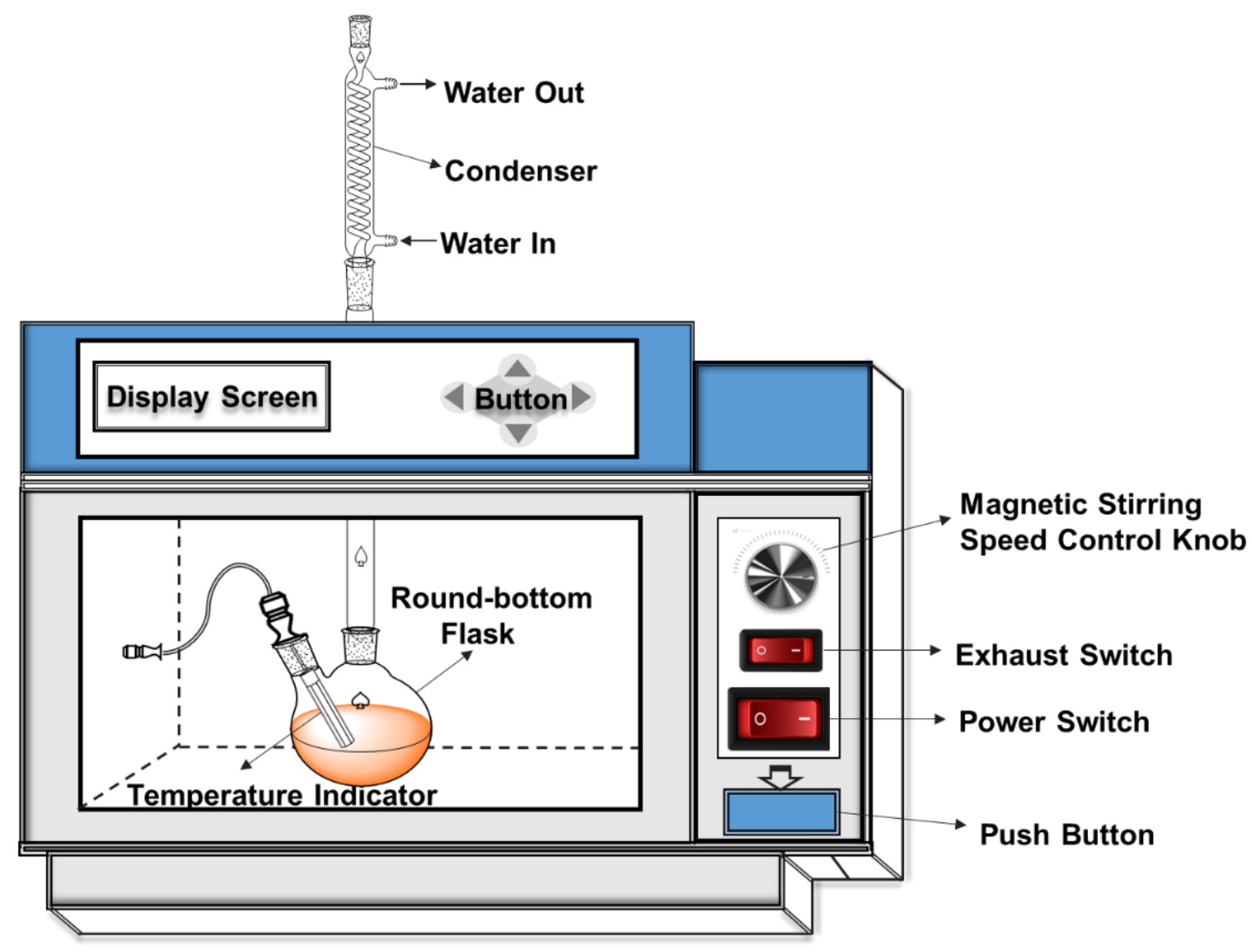

Fig. 1. Schematic diagram of the experimental setup for microwave-assisted extraction 


\section{Analytical Method}

Determination of total flavonoids content

The calibration curves were constructed using rutin solutions with different concentrations, i.e., 0.008, 0.016, 0.024, 0.032, 0.04, 0.048, 0.056, and $0.064 \mathrm{mg} / \mathrm{mL}$. According to the analysis of the calibration curves, the regression model of the linear relationship between the concentration of the rutin standard solution $(C)$ and the absorbency $(A)$ was obtained using Eq. 2,

$$
A=9.8938 C+0.0051
$$

where $R^{2}$ equals 0.9965 .

The total flavonoid content was determined by the colorimetric method with some modifications (Zhu et al. 2010; Lu et al. 2013). First, $1 \mathrm{~mL}$ of the sample solution and 1 $\mathrm{mL}$ of a $\mathrm{NaNO}_{2}(5 \%)$ solution were accurately added to a volumetric flask $(25 \mathrm{~mL})$; the mixture was mixed thoroughly and kept at room temperature $\left(25^{\circ} \mathrm{C}\right)$ for $5 \mathrm{~min}$. Second, 1 $\mathrm{mL}$ of an $\mathrm{Al}\left(\mathrm{NO}_{3}\right)_{3}(10 \%)$ solution was removed to the above flask and reacted for 6 min. Finally, $10 \mathrm{~mL}$ of a $\mathrm{NaOH}(4 \%)$ solution was added to the above volumetric flask, which was followed by adding alcohol (30\%) to the scale. After $20 \mathrm{~min}$, the absorbance of the resulting solution was measured at $510 \mathrm{~nm}$ using an ultraviolet-visible detector. The sample solution without coloration was used as a reference solution and the final data was presented as the mean of the three replicate measurements. The formula for calculating the extraction yield of flavonoids is shown in Eq. 3,

$$
Y=\frac{C \times V \times N}{1000 \mathrm{~m}} \times 100 \%
$$

where $Y(\%)$ is the extraction yield of flavonoids, $C(\mathrm{mg} / \mathrm{mL})$ is the flavonoid content of the test solution calculated by the linear regression model, $V(\mathrm{~mL})$ is the volume of the test solution, $N$ is the total dilution value, and $m(\mathrm{~g})$ is the mass of test sample.

\section{Fourier-transform infrared (FTIR) analysis}

Fourier-transform infrared (FTIR) spectra of the extracts were obtained using a Nicolet 6700 (Thermo Fisher Scientific, Waltham, MA) in the wavenumber range of 4000 to $400 \mathrm{~cm}^{-1}$ using a $\mathrm{KBr}$ disc containing approximately $1 \%$ finely ground samples.

\section{Scanning electron micrographs}

The surface morphology of the Phyllostachys heterocycla leaves after either the microwave-assisted extraction or traditional Soxhlet extraction were examined using a field-emission scanning electron microscope (SEM) (ZEISS Gemini 500, Oberkochen Germany) with InLens mode. The sample was fixed on the sample holder with conductive adhesive and a thin layer of gold was sputtered on the sample to render the surface conductive prior to examination.

\section{Evaluation for Antioxidant Activity}

$D P P H$ radical scavenging activity assay

The scavenging effect of the extracted flavonoids on the DPPH radicals was measured according to the previous report by Ge et al. (2020), with some modifications. Next, $600 \mu \mathrm{L}$ of different concentrations of the samples $(0.018$ to $0.18 \mathrm{mg} / \mathrm{mL})$ were added to separate glass test tubes. Then, $4 \mathrm{~mL}$ of $0.1 \mathrm{mM}$ DPPH $(0.1 \mathrm{mM}$ DPPH in ethanol was freshly prepared) was poured into each test tube. These two solutions were mixed 
thoroughly and stored at room temperature $\left(25^{\circ} \mathrm{C}\right)$ in the dark for 30 min. Finally, the absorbance of the resulting solution was measured at $517 \mathrm{~nm}$ using a UV/VIS spectrophotometer (TU-1900, Beijing Purkinje General Instrument Co., Ltd, Beijing, China). Vitamin $\mathrm{C}$ was used as a positive control. The DPPH radical-scavenging activity (\%) was calculated by Eq. 4,

$$
\text { DPPH scavenging effect }(\%)=\left(1-\frac{A_{x}-A_{x 0}}{A_{0}}\right) \times 100 \%
$$

where $A_{0}$ is the absorbance of the DPPH-ethanol solution mixed with ethanol, $A_{\mathrm{x}}$ is the absorbance of the DPPH-ethanol solution mixed with the sample solution, and $A_{\mathrm{x} 0}$ is the absorbance of ethanol mixed with the sample solution.

\section{ABTS radical scavenging activity assay}

The scavenging effect of the samples on the ABTS radicals was determined as described previously by $\mathrm{Hu}$ et al. (2016), with some modifications. First, ABTS stock solution with the concentration of $7.4 \mathrm{mM}$ was prepared, and then $5 \mathrm{~mL}$ of ABTS stock solution was mixed with $5 \mathrm{~mL}$ of $2.6 \mathrm{mM}$ potassium persulfate to prepare the ABTS reagent solution. This solution was stored at room temperature in the dark for $12 \mathrm{~h}$. In addition, the first thing to do when starting the ABTS assay is to dilute the ABTS reagent solution with a phosphate-buffered saline ( $\mathrm{pH} 7.4$ ) to maintain an absorbance of $0.70 \pm 0.02$ at $734 \mathrm{~nm}$. Then, $400 \mu \mathrm{L}$ of the sample of different concentrations was added to $4 \mathrm{~mL}$ of the diluted ABTS solution to react in the dark at a temperature of $30{ }^{\circ} \mathrm{C}$ for 6 min. Finally, the absorbance of the mixture was measured at a wavelength of $734 \mathrm{~nm}$. Vitamin $\mathrm{C}$ was used as a positive control. ABTS radical-scavenging activity (\%) was calculated with Eq. 5,

$$
\text { ABTS scavenging effect }(\%)=\left(1-\frac{A_{x}}{A_{0}}\right) \times 100 \%
$$

where $A_{0}$ is the absorbance of the diluted ABTS solution mixed with ethanol, and $A_{\mathrm{x}}$ is the absorbance of the diluted ABTS solution mixed with the sample solution.

\section{RESULTS AND DISCUSSION}

\section{Analysis of the Singal Factor and Plackett-Burman Experimental Results}

The effects of different factors on the total flavonoid extraction yield are shown in Figs. 2a through 2 d. For instance, in Fig. 2a, the total flavonoid extraction yield increased as the ethanol concentration increased, before achieving the highest extraction yield $(4.26 \%)$ at an ethanol concentration of $70 \%$, and then the yield rapidly decreased. A possible explanation for this phenomenon might be that the increase in the ethanol proportion in the extraction solvent will gradually reduce the solvent polarity (Butsat and Siriamornpun 2016). Furthermore, a high concentration of ethanol may hold back the dissolution of polyphenols, thereby affecting the extraction yield (Bouras et al. 2015; Ghaffar et al. 2020; Petrotos et al. 2021). In consideration to the limitation of the ethanol proportion, a $60 \%$ to $80 \%$ (v/v) ethanol concentration was used as the optimal range for the Plackett-Burman experiment. Regarding the influence of the solid to liquid ratio (as shown in Fig. 2b), the flavonoid extraction yield showed a downward trend when the solid to liquid ratio exceeded 1 to 30 , which may be explained by the fact that the solid to liquid ratio of 1 to 30 was more suitable to completely extract the soluble flavonoids. 
Regarding the influence of the extraction time (as shown in Fig. 2c), the extraction yield showed a prominent increase during the range of 5 to $20 \mathrm{~min}$. However, the yield began to decrease when the extraction time exceeded $20 \mathrm{~min}$, which indicated that too long an extraction time may lead to the decomposition of flavonoids (Su et al. 2019). In terms of microwave power (Fig. 2d), as the microwave power increased from 160 to $640 \mathrm{~W}$, the flavonoid yield gradually increased until it reached its maximum value at $480 \mathrm{~W}$. However, the extraction yields dropped as the microwave power was further increased. The preliminary improvement to the yield at an elevated microwave power could be attributed to the increased destruction of the cellular structure, which can be explained by the rapid pressure built up in the cellular matrix and the corresponding increase in temperature due to dielectric heating (Wang et al. 2012; Routray and Orsat 2014; He et al. 2016; Zhong et al. 2016). However, a high microwave power might increase the temperature of the flavonoids too much and decrease the extraction yield due to the breakdown of the flavonoid structure (Ma et al. 2009).

Based on the above results, the optimal conditions amongst the four parameters tested were evaluated as follows: an ethanol concentration of $70 \%$, solid to liquid ratio of 1 to 30 , extraction time of $20 \mathrm{~min}$, and the microwave power of $480 \mathrm{~W}$, which resulted in a flavonoid extraction yield of $4.26 \%$. Similar studies have been investigated by Lu et al. (2013), who found that the highest flavonoid yield (2.70\%) extracted from Cryptotaenia japonica Hassk was achieved at a solid to liquid ratio of 1 to 20 using $70 \%$ (v/v) ethanol for $15 \mathrm{~min}$.

To further select the significant variables for the extraction of flavonoids, the ethanol concentration, solid to liquid ratio, extraction time, and microwave power were tested and identified via the Plackett-Burman design experiment. The experimental design with the name, symbol code, and actual level of the variables are presented in Table 1 . The corresponding responses are shown in Table 2. The adequacy of the model was calculated, and the variables evidencing statistically significant effects were screened via Student's ttest for ANOVA (Table 3).

In addition, factors were selected for further optimization studies with $p$-values of less than 0.05 suggesting significant effects on the response. The ethanol concentration was determined to be the most significant factor with a probability value of 0.000 , followed by microwave power (0.004), and extraction time (0.007). A lower probability values indicates a more significant factor on the flavonoid extraction yield. The insignificant variable, i.e., the solid to liquid ratio, was neglected, and the optimum levels of the three variables, i.e., the ethanol concentration, extraction time and microwave power, were further determined via an RSM design.

The Pareto chart indicating the significant factors for the flavonoid extraction process is shown in Fig. 3. It showed the standardized effect of each parameter or the combination of parameters, as calculated by Eq. 6,

$$
Y=3.3592+0.01842 X_{1}-0.00492 X_{2}+0.01817 X_{3}-0.09916 X_{4}
$$

where $Y$ is the response (the flavonoid extraction yield), and the coefficient of each parameter reveals the effect of the parameters on the extraction process. Among these parameters, the ethanol concentration and extraction time exerted positive effects, whereas the microwave power and solid to liquid ratio exerted negative effects. 

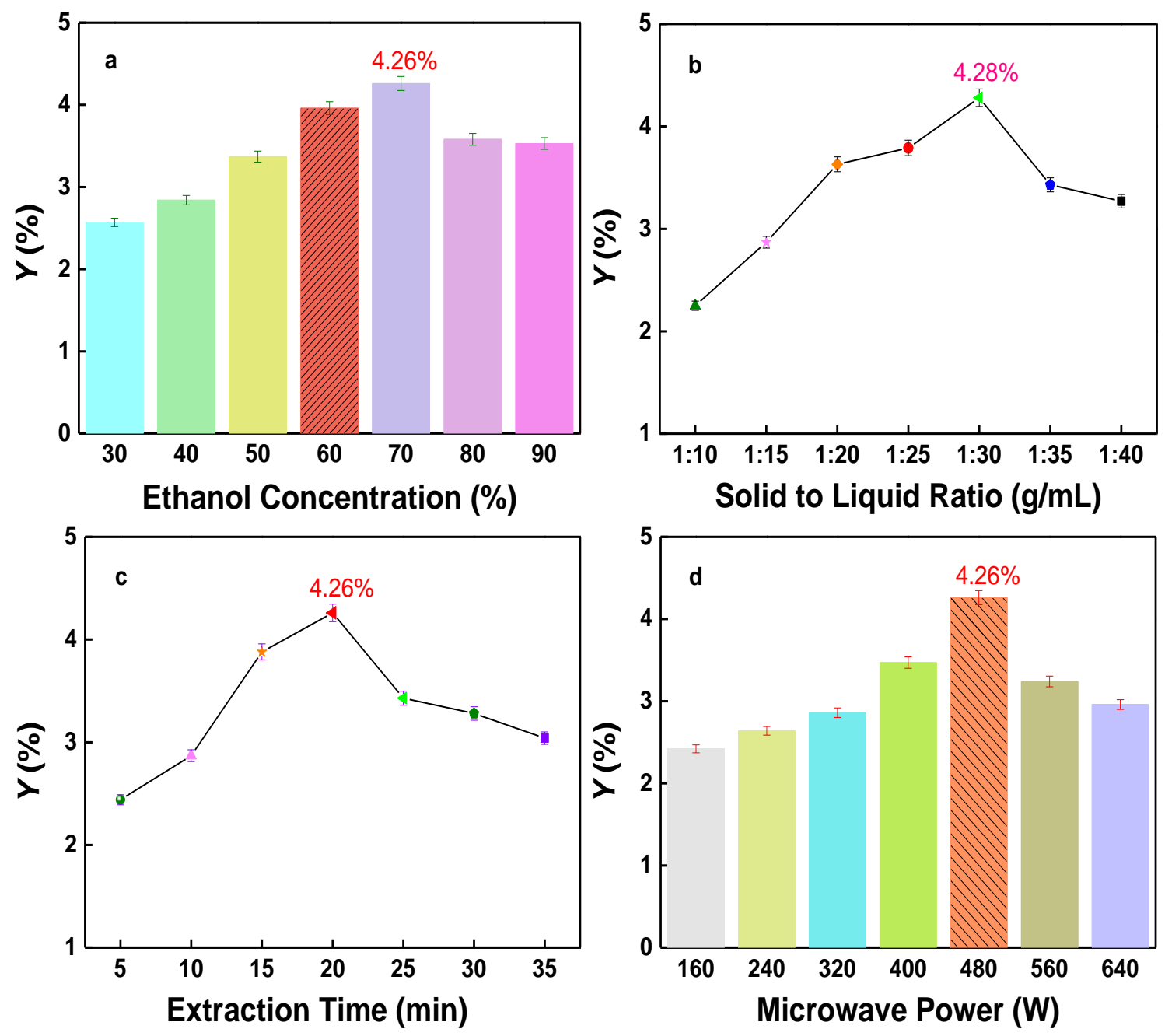

Fig. 2. Effect of the ethanol concentration (a); solid to liquid ratio (b); extraction time (c); and microwave power (d) on the total flavonoid extraction yield

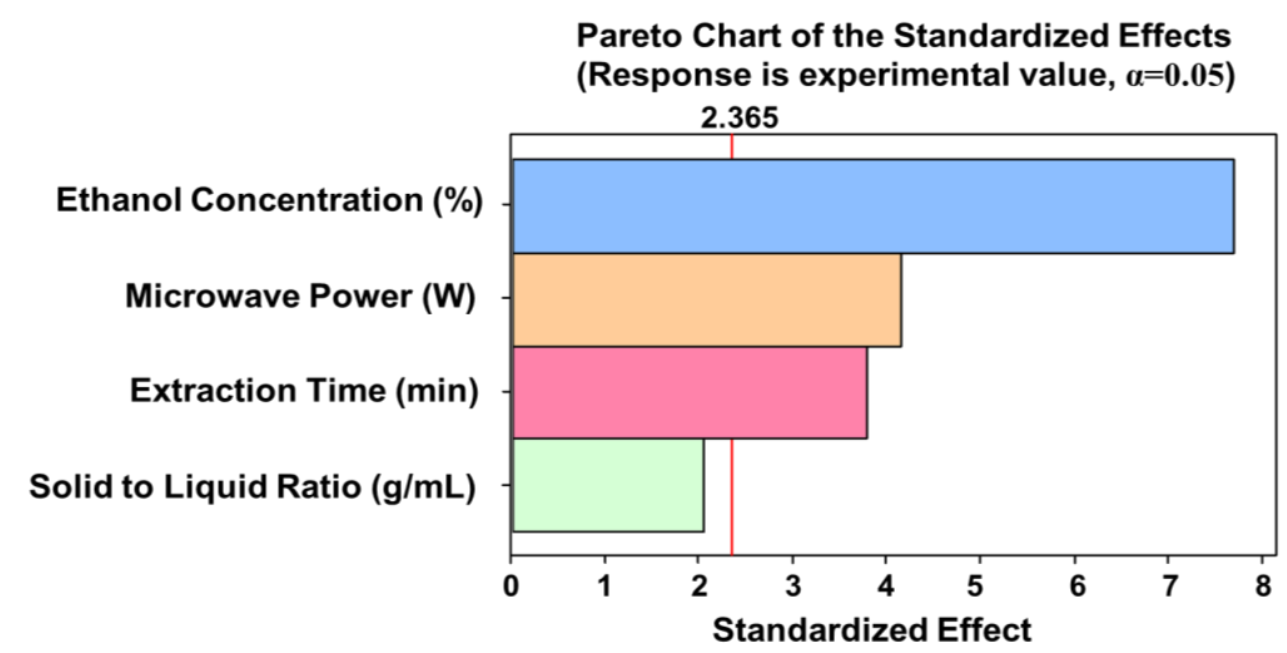

Fig. 3. Pareto chart indicating the significant parameters 
Table 1. Experimental Variables at Different Levels Used for the MicrowaveAssisted Extraction of Flavonoids Using the Plackett-Burman Design

\begin{tabular}{|c|c|c|c|}
\hline \multirow{2}{*}{ Variables } & \multirow{2}{*}{ Symbol Code } & \multicolumn{2}{|c|}{ Experimental Values } \\
\cline { 3 - 4 } & & Low $(-1)$ & High $(+1)$ \\
\hline Ethanol concentration $(\%)$ & $\mathrm{X}_{1}$ & 60 & 80 \\
\hline Solid to liquid ratio $(\mathrm{g} / \mathrm{mL})$ & $\mathrm{X}_{2}$ & $1: 20$ & $1: 40$ \\
\hline Extraction time $(\mathrm{min})$ & $\mathrm{X}_{3}$ & 15 & 25 \\
\hline Microwave power $(\mathrm{W})$ & $\mathrm{X}_{4}$ & 400 & 560 \\
\hline
\end{tabular}

Table 2. The Twelve-Trial Plackett-Burman Design Matrix of the Four Variables with Actual Values

\begin{tabular}{|c|c|c|c|c|c|}
\hline Number & $X_{1}(\%)$ & $X_{2}(\mathrm{~g} / \mathrm{mL})$ & $X_{3}(\min )$ & $X_{4}(\mathrm{~W})$ & $Y(\%)$ \\
\hline 1 & 60 & 20 & 15 & 400 & 4.23 \\
\hline 2 & 60 & 40 & 25 & 400 & 4.27 \\
\hline 3 & 80 & 40 & 15 & 560 & 4.24 \\
\hline 4 & 60 & 20 & 25 & 560 & 4.21 \\
\hline 5 & 80 & 40 & 15 & 560 & 4.24 \\
\hline 6 & 80 & 40 & 25 & 400 & 4.63 \\
\hline 7 & 60 & 20 & 15 & 560 & 3.86 \\
\hline 8 & 60 & 40 & 25 & 560 & 3.96 \\
\hline 9 & 80 & 20 & 25 & 400 & 4.58 \\
\hline 10 & 80 & 20 & 25 & 560 & 4.51 \\
\hline 11 & 60 & 40 & 15 & 400 & 3.98 \\
\hline 12 & 80 & 20 & 15 & 400 & 4.52 \\
\hline
\end{tabular}

Table 3. Estimated Effect, Regression Coefficient, and Corresponding t-value and $p$-value for the Flavonoid Extraction Yield of the Four Variables PlackettBurman Design Experiment

\begin{tabular}{|c|c|c|c|c|c|}
\hline Variables & Effect & Coefficient & Standard Error & t-value & $p$-value \\
\hline Ethanol Concentration $(\%)$ & 0.368 & 0.184 & 0.024 & 7.70 & $0.000^{\mathrm{b}}$ \\
\hline Solid to Liquid Ratio $(\mathrm{g} / \mathrm{mL})$ & -0.098 & -0.049 & 0.024 & -2.06 & $0.079^{\mathrm{a}}$ \\
\hline Extraction Time $(\mathrm{min})$ & 0.182 & 0.091 & 0.024 & 3.80 & $0.007^{\mathrm{b}}$ \\
\hline Microwave Power $(\mathrm{W})$ & -0.198 & -0.099 & 0.024 & -4.15 & $0.004^{\mathrm{c}}$ \\
\hline
\end{tabular}

Note: $\mathrm{a}$ is non-significant at a $p$-value greater than 0.05 ; $\mathrm{b}$ is a significant positive effect; and $\mathrm{c}$ is a significant negative effect

\section{Statistical Analysis and Model Fitting of the Flavonoid Extraction Process}

The three independent variables, i.e., concentration of ethanol $(A)$, extraction time $(B)$, microwave power $(C)$, and their levels in the response surface design are shown in the Table 4 . The response surface analysis of the flavonoid yield varying with $A, B$, and $C$ is presented in Table 5. The second-order polynomial model for the relationship between the independent variables and the flavonoid extraction yield $(Y)$ was established as shown in Eq. 7, 


$$
\begin{aligned}
& Y=4.10+0.1150 A+0.0988 B+0.0662 C+0.2025 A B- \\
& 0.1725 A C-0.0400 B C-0.0250 A^{2}+0.1225 B^{2}+0.2625 C^{2}
\end{aligned}
$$

It can be seen from the data in Table 6 that the proposed regression model for the flavonoid extraction yield had a satisfactory determination coefficient $\left(\mathrm{R}^{2}\right)$ value and no significant value of the lack of fit (0.1644). The $\mathrm{R}^{2}$ value was $99.07 \%$, which indicated a reasonable correlation between the experimental results and the theoretical values. In addition, the $p$-values were applied to check the significance of each variable. As shown in Table 6 , the linear terms of ethanol concentration $(A)$, extraction time $(B)$, and microwave power $(C)$, as well as the quadratic terms of extraction time $\left(B^{2}\right)$ and microwave power $\left(C^{2}\right)$ showed significant ( $p$-value was less than 0.05 ) effects on the flavonoid extraction process. Among the interaction terms, $A B$ and $A C$ were significant ( $p$-value was less than 0.05 ) for this extraction process.

Table 4. Independent Variables and Their Levels in the Response Surface Design

\begin{tabular}{|c|c|c|c|c|}
\hline \multicolumn{2}{|c|}{ Independent Variables } & \multicolumn{3}{c|}{ Coded Factor Level } \\
\cline { 3 - 5 } \multicolumn{2}{|c|}{} & -1 & 0 & 1 \\
\hline$A$ & Ethanol concentration (\%) & 60 & 70 & 80 \\
\hline$B$ & Extraction time (min) & 15 & 20 & 25 \\
\hline$C$ & Microwave power (W) & 400 & 480 & 560 \\
\hline
\end{tabular}

Table 5. Results of the Response Surface Analysis of the Variation in Flavonoid Yield

\begin{tabular}{|c|c|c|c|c|}
\hline Number & $A(\%)$ & $B(\min )$ & $C(\mathrm{~W})$ & $Y(\%)$ \\
\hline 1 & 70 & 20 & 480 & 4.12 \\
\hline 2 & 70 & 15 & 400 & 4.25 \\
\hline 3 & 70 & 25 & 560 & 4.64 \\
\hline 4 & 60 & 20 & 400 & 3.99 \\
\hline 5 & 70 & 25 & 400 & 4.58 \\
\hline 6 & 60 & 20 & 560 & 4.46 \\
\hline 7 & 70 & 20 & 480 & 4.06 \\
\hline 8 & 70 & 15 & 560 & 4.47 \\
\hline 9 & 80 & 20 & 400 & 4.56 \\
\hline 10 & 80 & 15 & 480 & 4.04 \\
\hline 11 & 60 & 15 & 480 & 4.21 \\
\hline 12 & 80 & 25 & 480 & 4.59 \\
\hline 13 & 80 & 20 & 560 & 4.34 \\
\hline 14 & 70 & 20 & 480 & 4.11 \\
\hline 15 & 70 & 20 & 480 & 4.12 \\
\hline 16 & 70 & 20 & 480 & 4.09 \\
\hline 17 & 60 & 25 & 480 & 3.95 \\
\hline
\end{tabular}

The scatter diagram of the predicted results versus the actual values for the flavonoid yield is shown in Fig. 4. The predicted values obtained by the regression equation matched the experimental values reasonably well with an $\mathrm{R}^{2}$ value of $99.07 \%$. Moreover, adequate precision (AP) was applied to compare the range of the predicted values at the design points to the average prediction error (Fig. 4). According to Table 6, the AP values (24.08) higher than four confirmed that the predicted model can be used to navigate the 
design space. The coefficient of variance $(\mathrm{CV})$ as the ratio of the estimated standard error to the average of the observed response defines the reproducibility of the model. The CV values $(0.81 \%)$ in Table 6 was less than $10 \%$, which demonstrated that the model can be considered reproducible (Ghafari et al. 2009). Similarly, the normal probability distribution diagram of the residuals is shown in Fig. 5. It was found that the externally studentized residuals were also distributed on the straight line with a $45^{\circ}$ slope, which satisfied the normal hypothesis. From this analysis, it was found that the established regression model could approximately predict the flavonoid extraction yield.

Table 6. Variance Analysis of Regression Model

\begin{tabular}{|c|c|c|c|c|c|}
\hline Source & Degree of Freedom & Sum of Square & Mean Square & $F$ Value & $P_{r}>F$ \\
\hline Model & 9 & 0.8770 & 0.0974 & 82.43 & $<0.0001$ \\
\hline$A$ & 1 & 0.1058 & 0.1058 & 89.50 & $<0.0001$ \\
\hline$B$ & 1 & 0.0780 & 0.0780 & 65.99 & $<0.0001$ \\
\hline$C$ & 1 & 0.0351 & 0.0351 & 29.70 & 0.0010 \\
\hline$A B$ & 1 & 0.1640 & 0.1640 & 138.75 & $<0.0001$ \\
\hline$A C$ & 1 & 0.1190 & 0.1190 & 100.69 & $<0.0001$ \\
\hline$B C$ & 1 & 0.0064 & 0.0064 & 5.41 & 0.0529 \\
\hline$A^{2}$ & 1 & 0.0026 & 0.0026 & 2.23 & 0.1793 \\
\hline$B^{2}$ & 1 & 0.0632 & 0.0632 & 53.45 & 0.0002 \\
\hline$C^{2}$ & 1 & 0.2901 & 0.2901 & 245.43 & $<0.0001$ \\
\hline Residual & 7 & 0.0083 & 0.0012 & & \\
\hline Lack of fit & 3 & 0.0057 & 0.0019 & 2.91 & 0.1644 \\
\hline Note: $R^{2}$ equals $99.07 \%$ AP equals $24.08 ;$ CV equals $0.81 \% ;$ and $P_{r}$ was less than 0.0001 \\
\hline
\end{tabular}

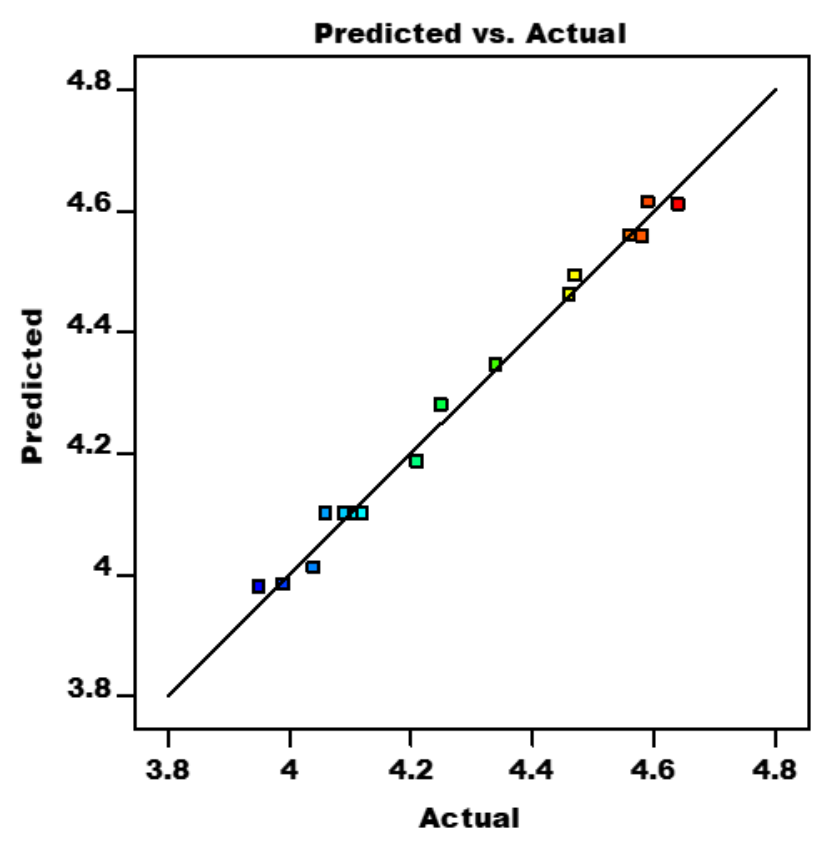

Fig. 4. Scatter diagram of the predicted results versus the actual values for the flavonoid yield

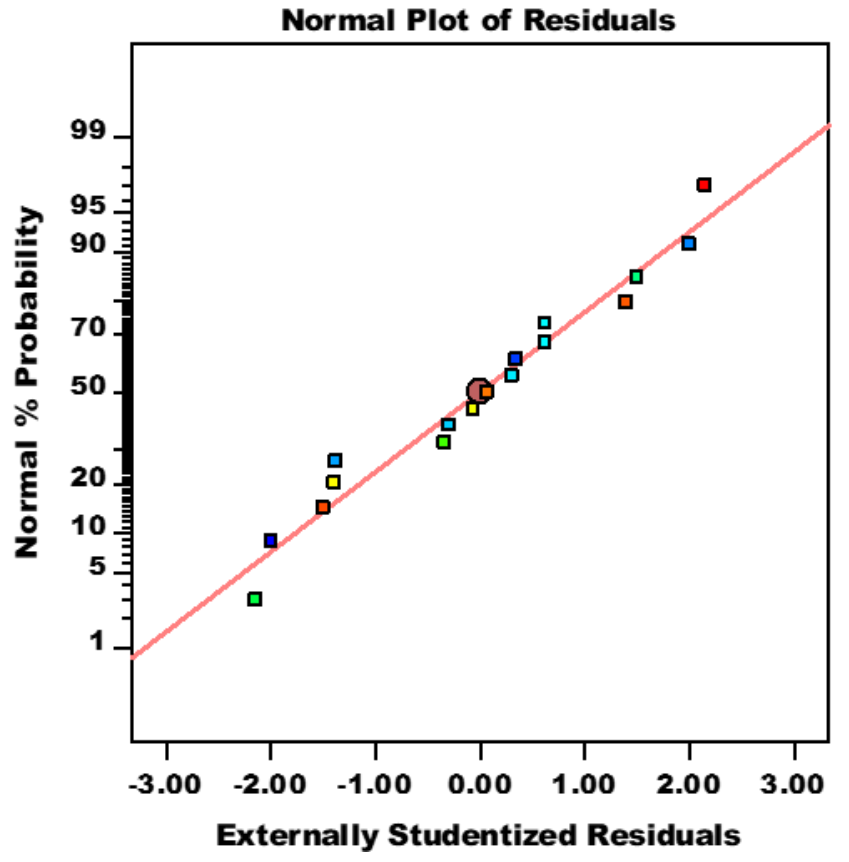

Fig. 5. The normal probability distribution of the residuals 

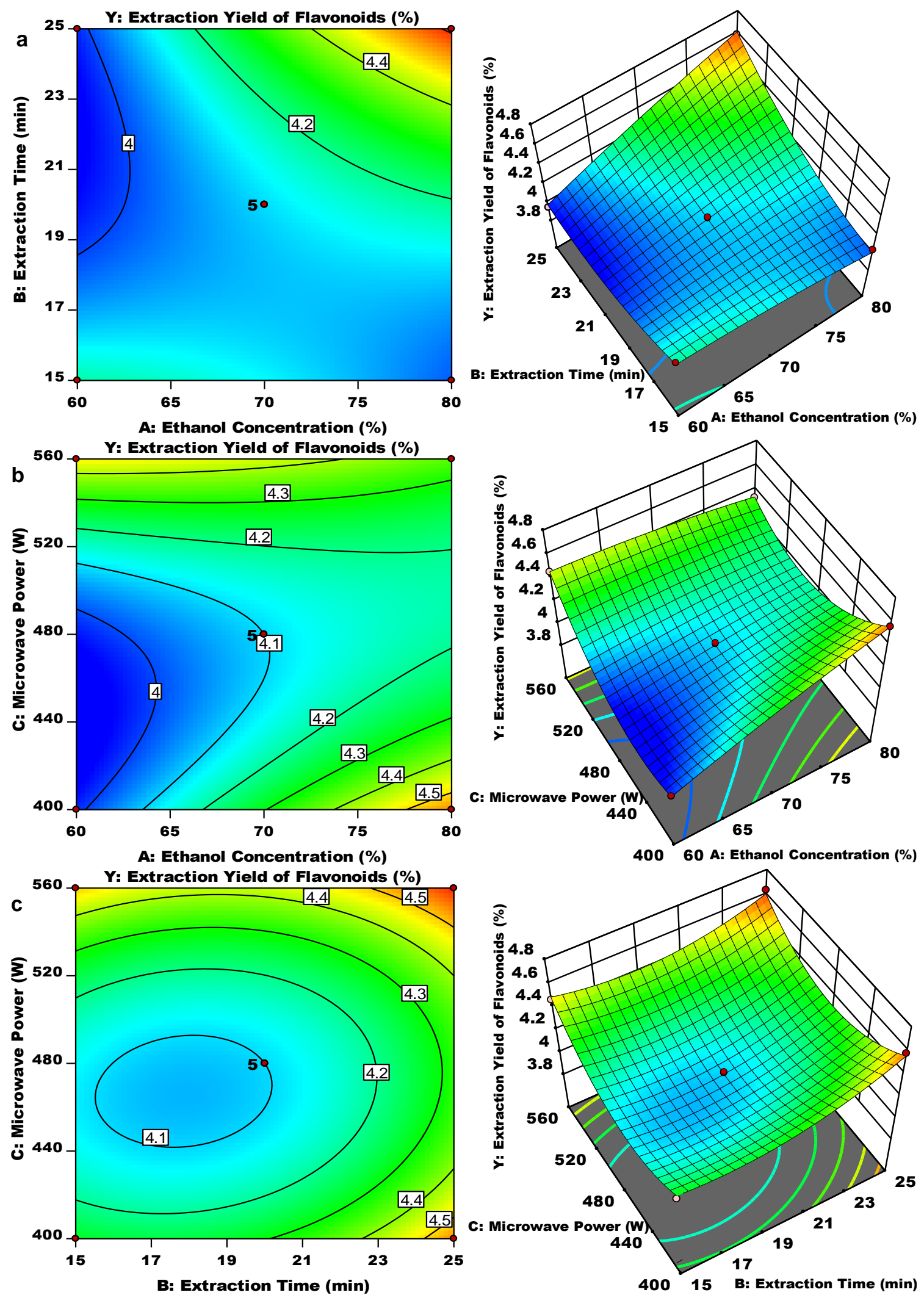

Fig. 6. The contour plots and response surface demonstrating the effect of a (ethanol concentration and extraction time), $b$ (ethanol concentration and microwave power), and $c$ (extraction time and microwave power) on the yield of flavonoids. 


\section{Optimization of the Microwave-Assisted Extraction Conditions and Validation of the Models}

The contour plots and 3-D response surface plots obtained using the Design Expert 8.0 software are shown in Figs. 6a through 6c. Through these graphs, the visual interaction between two extraction variables on the flavonoid yield can be determined (CardosoUgarte et al. 2014). Figure 6a demonstrated the effect of the ethanol concentration and extraction time on the flavonoid yield. The positive coefficient of the term $A B$ (refer to Eq. 7) confirmed the prominent interaction effect on the flavonoid yield. It was evident that with an increase in ethanol concentration or extraction time, the flavonoid yield gradually increased. In addition, the $p$-value of $A B$, which was less than 0.05 , indicated significant interaction of the ethanol concentration and extraction time. The plot of the effect of the ethanol concentration and microwave power to raw material on the flavonoid yield is shown in Fig. 6b. The flavonoid yield significantly increased as the ethanol concentration and microwave power increased. Figure $6 \mathrm{c}$ predicted the mutual effect of the extraction time and microwave power on the flavonoid yield. It can be observed from the plot that there was a marginal increase in the flavonoid yield when the extraction time and the microwave power increased from $400 \mathrm{~W}$ and $15 \mathrm{~min}$ to $480 \mathrm{~W}$ and $20 \mathrm{~min}$, respectively.

Based on the established quadratic regression model, the optimal extraction conditions were as follows: an ethanol concentration of $78.1 \%$, an extraction time of 24.9 min, and a microwave power of $559 \mathrm{~W}$. Under these optimal conditions, the predicted flavonoid yield was $4.70 \%$. The validation was performed under these conditions, modified for convenience, as follows: the ethanol concentration was $78 \%$, the extraction time was $25 \mathrm{~min}$, and the microwave power was $560 \mathrm{~W}$. The obtained actual flavonoid yield was $4.67 \%$, which not only indicated that there were no remarkable differences between the experimental and predicted values, but also verified that this quadratic regression model was feasible in terms of simulation and able to predict experimental results in practice.

\section{Comparison of the Microwave-Assisted Extraction and the Traditional Soxhlet Extraction}

The application of microwave-assisted extraction had a positive effect on the flavonoid yield compared with traditional Soxhlet extraction, and the results are summarized in Table 7. Under the optimal conditions of microwave-assisted extraction, the flavonoid yield increased from $3.35 \%$ to $4.67 \%$ with a notably shorter extraction time (25 min), which demonstrated that this method could not only increase the extraction yield, but also greatly shorten the extraction time (Ho et al. 2019). These findings were consistent with those reported in the literature, which have shown that applying microwave-assisted extraction to any number of materials can considerably reduce the extraction time compared to conventional extraction methods (Zhang et al. 2011; Tanongkankit et al. 2013; Geetha et al. 2019).

Table 7. Comparison of the Microwave-Assisted Extraction and Traditional Soxhlet Extraction in Terms of the Flavonoid Yield from Phyllostachys heterocycla Leaves

\begin{tabular}{|c|c|c|}
\hline Methods & Extraction Time (min) & Y (\%) \\
\hline Microwave-assisted extraction & 25 & 4.67 \\
\hline Traditional Soxhlet extraction & 420 & 3.35 \\
\hline
\end{tabular}

Xu et al. (2021). "Microwave extraction of flavonoids," BioResources 16(4), 8060-8081. 
In order to explore the essential differences between the microwave-assisted extraction and traditional Soxhlet extraction, a possible extraction mechanism was proposed (Fig. 7). When dry bamboo leaf particles were extracted with ethanol, the extraction process was divided into three steps: First, the ethanol surrounded the bamboo leaf particles to create a solvent film and swelling occurs (Vinatoru et al. 2017). The shape of the bamboo leaf particles, which were initially irregular, became rounded and smooth. During the swelling process, the solvent entered the bamboo leaf particle matrix and the flavonoids were released into the solvent (type II diffusion, as shown in Fig. 7). At the end of the swelling period, the bamboo leaf particles were surrounded by a solvent layer to form a "stagnant layer", which will hinder the extraction. Second, the flavonoids diffused from the solvated bamboo leaf particles to the stagnant layer (type I diffusion, as shown in Fig. 7). Third, the flavonoids proliferated from the stagnant layer into the bulk solvent (type III diffusion, as shown in Fig. 7). However, the major difference between these two extraction methods is that the bamboo leaf particles can quickly reach a higher temperature under microwave irradiation than traditional Soxhlet extraction and steam is created within the cellular structures, which increases the inside cell pressure, leading to the rupture of the cell membranes; hence the extraction efficiency is improved (Gao et al. 2004; Li et al. 2013; Lee et al. 2016). In addition, this effect also enhances the rinsing out of the contents of the broken cells and facilitates the release of more active compounds.

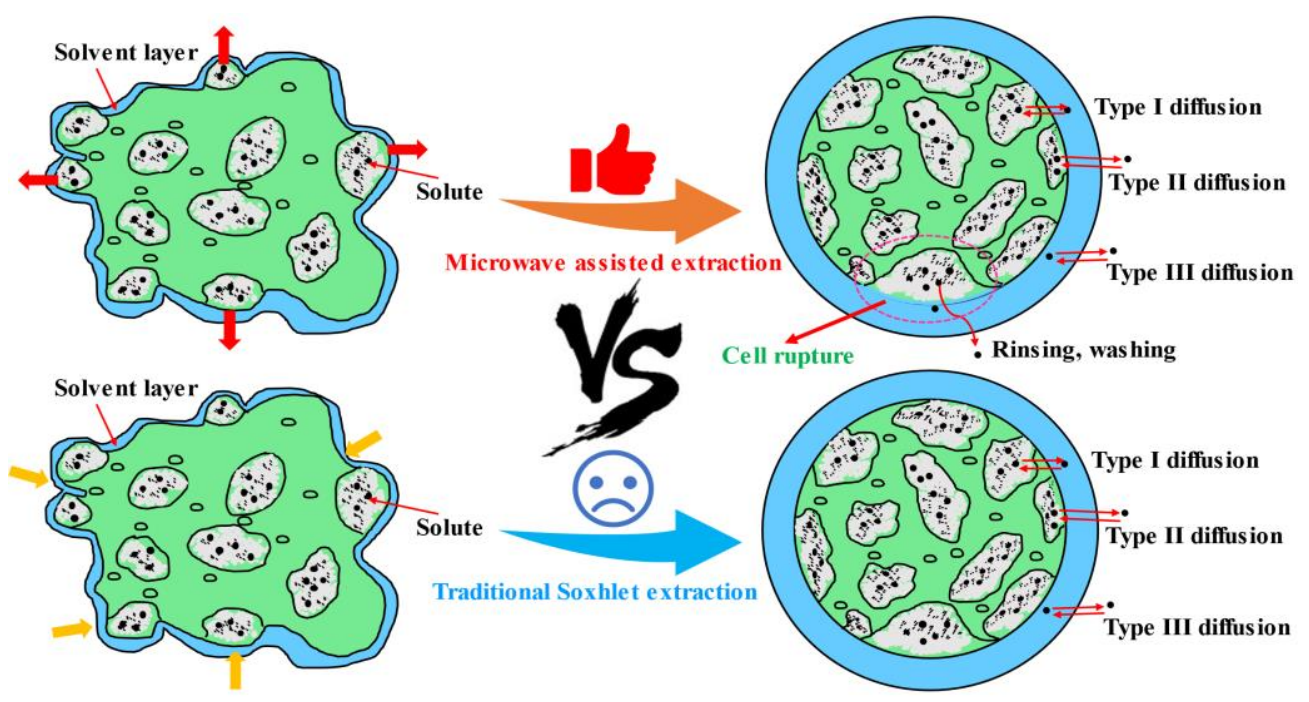

Fig. 7. Possible extraction mechanism (microwave-assisted extraction versus traditional Soxhlet extraction)

The scanning electron micrographs of the raw material (Phyllostachys heterocycla leaves) and the materials treated via microwave-assisted extraction and traditional Soxhlet extraction are shown in Fig. 8. The surface of the Phyllostachys heterocycla leaves before extraction (Fig. 8a) are planar and smooth. After the traditional Soxhlet extraction, no appreciable changes could be found in the surfaces of the samples (Fig. 8c). However, the scanning electron micrograph of the Phyllostachys heterocycla leaves after the microwaveassisted extraction revealed the presence of several long cracks distributed across the entire particle. This phenomenon was attributed to the sudden thermal stresses and the high localized pressures, thereby causing ruptures and creases in the cell structure (Kaderides $e t$ al. 2019). Similarly, studies carried out by Alara et al. (2019) have revealed that microwave 
radiation plays a vital role in the rupture of vegetal cell walls and this structural change in the cell walls allows the solvent to easily enter the cellular channels with high extraction efficiency. All of these analyses confirmed that microwave-assisted extraction should be more suitable for extracting flavonoids from Phyllostachys heterocycla leaves than the traditional Soxhlet extraction.
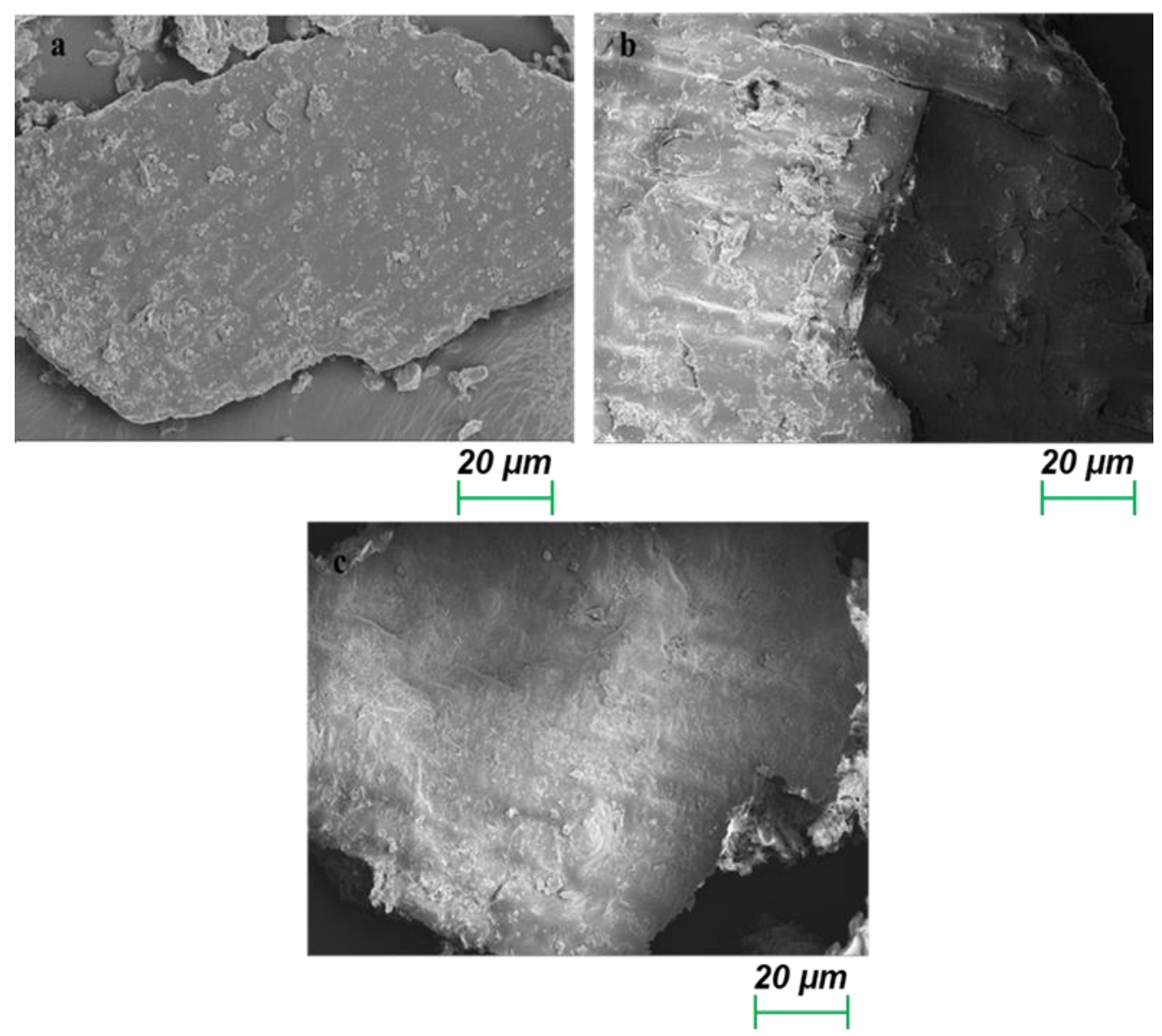

Fig. 8. Scanning electron micrographs (magnification $500 \mathrm{X}$ ) of the Phyllostachys heterocycla leaves: (a) untreated; (b) after microwave-assisted extraction; and (c) after traditional Soxhlet extraction

\section{Fourier-transform Infrared (FTIR) Analysis}

Fourier-transform infrared spectroscopy is a powerful non-destructive analytical technique for the chemical characterization of different compounds, which provides basic information on the molecular structure of organic compounds in plant extracts (Patle et al. 2020). In order to demonstrate the effect of microwave-assisted extraction and traditional Soxhlet extraction on the flavonoid functional groups, the infrared spectrum of the flavonoids extracted from Phyllostachys heterocycla leaves via two methods, within a frequency range of 4000 to $400 \mathrm{~cm}^{-1}$, were analyzed (Fig. 9). The FTIR bands in the range of 4000 to $1500 \mathrm{~cm}^{-1}$ and 1500 to $500 \mathrm{~cm}^{-1}$ represented the functional group and the fingerprint region, respectively. There was a broad absorption peak at $3419 \mathrm{~cm}^{-1}$, which was assigned to the stretching vibration of the $\mathrm{O}-\mathrm{H}$ group. The low-intensity absorption band at $2930 \mathrm{~cm}^{-1}$ was attributed to the $-\mathrm{CH}$ stretching (Karpagasundari and Kulothungan 2014). A prominent peak at $1628 \mathrm{~cm}^{-1}$ was due to the stretching of the carbonyl $(\mathrm{C}=\mathrm{O})$ 
group in the compound and the minor changes in bands at 1500 to $1400 \mathrm{~cm}^{-1}$ can be attributed to the stretching of C-O. The absorption peak nearby 1118 to $1100 \mathrm{~cm}^{-1}$ was assigned to the stretching vibration of the C-O-C group and the band at 800 to $600 \mathrm{~cm}^{-1}$ was allocated to the substitutions of the Ar-H group (Meenakshi et al. 2009; Hamad et al. 2012; Patle et al. 2020). From this analysis (Fig. 9), the functional groups of the flavonoids extracted via microwave-assisted extraction and traditional Soxhlet extraction were fundamentally identical, which confirmed that microwave-assisted extraction had no effect on the flavonoid functional groups and should be an efficient and suitable technique.

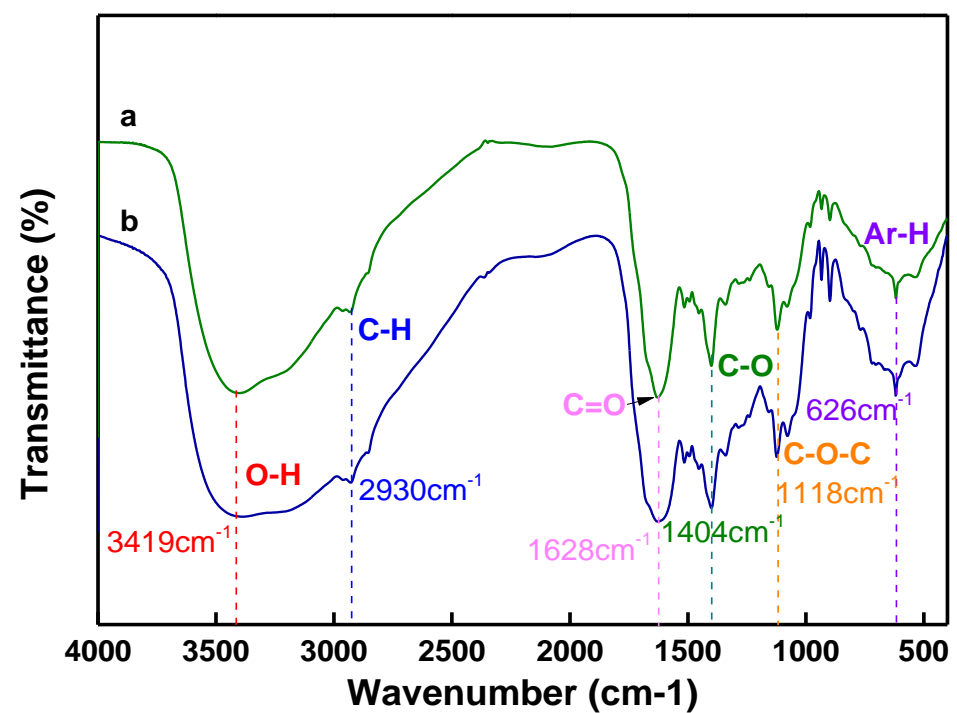

Fig. 9. The FTIR spectra of the flavonoids from Phyllostachys heterocycla leaves extracted with different methods (Note: 'a' means microwave-assisted extraction; and 'b' means Soxhlet extraction)

\section{Evaluation of the Antioxidant Activities of the Flavonoids Obtained Under Optimal Conditions}

The antioxidant potential of plant extracts is often determined by in vitro antioxidant activity assays, e.g., the DPPH radical scavenging assay (Mišan et al. 2020; Chen et al. 2021). In the present work, the antioxidant activities of the flavonoids obtained under optimal microwave-assisted extraction conditions were performed by two antioxidant assays, i.e., DPPH and ABTS. As shown in Fig. 10, the free radical scavenging activities of the flavonoids and vitamin $\mathrm{C}$ in the DPPH and ABTS experiments follow the same trend as the concentration increased. The DPPH radical scavenging activity of the flavonoids at each concentration was lower than radical scavenging activity of vitamin $\mathrm{C}$. According to the different concentrations of the clearance curve, the half-maximal inhibitory concentration (IC50) was used to compare the radical scavenging activity of the flavonoids, and the lower IC50 value, the better it can scavenge radicals. As observed from Fig. 10, the flavonoids had a considerably higher IC50 value $(0.0734 \mathrm{mg} / \mathrm{mL})$ compared to vitamin $\mathrm{C}(0.0277 \mathrm{mg} / \mathrm{mL})$, which demonstrated that the antioxidant activities of the flavonoids extracted from Phyllostachys heterocycla leaves were lower than the antioxidant activities of vitamin C. However, the result of the flavonoids in the DPPH assay was $84.1 \%$ based on a $0.18 \mathrm{mg} / \mathrm{mL}$ sample, which revealed that the flavonoids extracted from the Phyllostachys heterocycla leaves had excellent antioxidant activity. In addition, the radical scavenging activity of the flavonoids in the ABTS assay was higher than the 
radical scavenging activity of vitamin $\mathrm{C}$, and at the highest concentration $(0.18 \mathrm{mg} / \mathrm{mL})$, $98.4 \%$ of scavenging potential was observed. The IC50 value for the flavonoids $(0.019$ $\mathrm{mg} / \mathrm{mL}$ ) in the ABTS assay was found to be lower when compared to vitamin $\mathrm{C}$, which indicated that the ABTS radical scavenging activity of the total flavonoids extracted from Phyllostachys heterocycla leaves was higher than vitamin C. Overall, the results suggested that Phyllostachys heterocycla leaves could be a new natural source for developing antioxidants in the clinical industry.
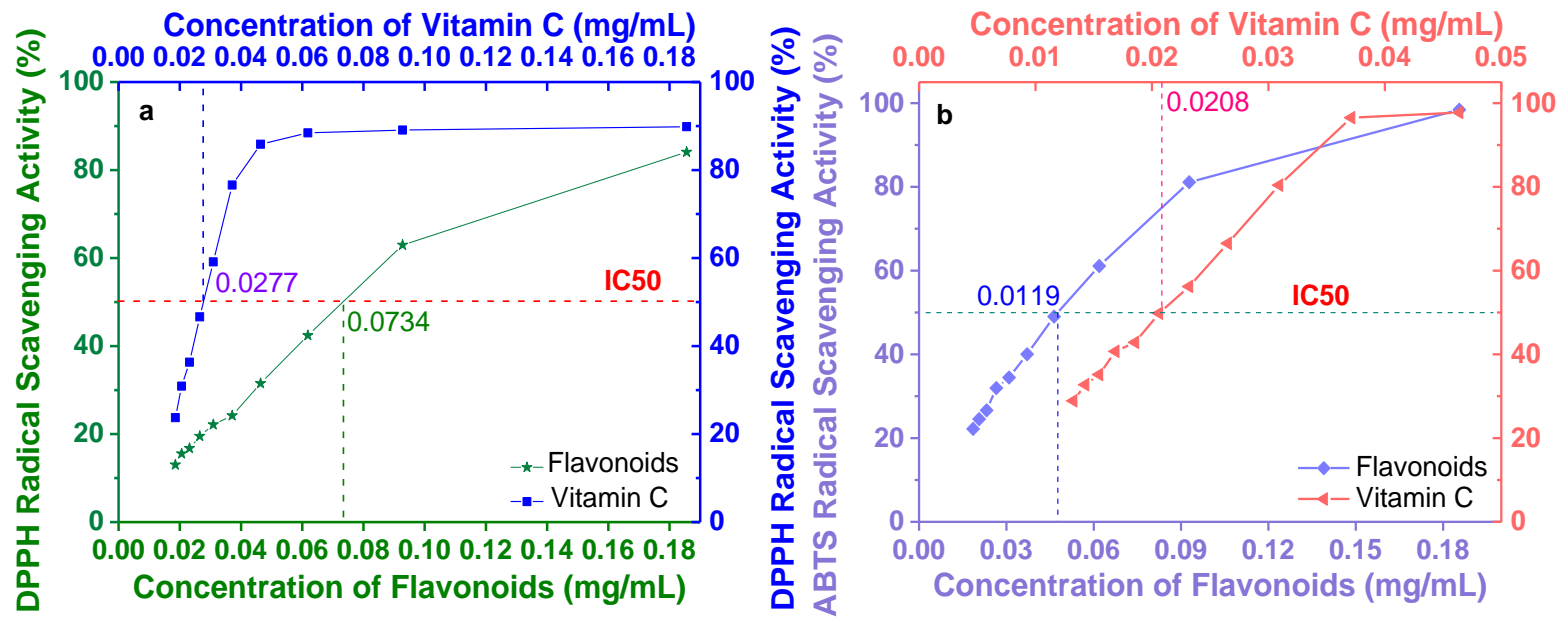

Fig. 10. Antioxidant activities of the flavonoids and vitamin C: (a) DPPH assay; and (b) ABTS assay

\section{CONCLUSIONS}

1. Based on the results of the single-factor experiments, the three significant variables, i.e., ethanol concentration, extraction time, and microwave power, for the extraction of flavonoids were selected through the Plackett-Burman experiment. In addition, the optimal conditions for extracting flavonoids were further determined by an RSM design. The optimal microwave-assisted extraction conditions for flavonoids were obtained, as follows: an ethanol concentration of $78.1 \%$, an extraction time of $24.9 \mathrm{~min}$, and a microwave power of $559 \mathrm{~W}$. Compared with traditional Soxhlet extraction, the microwave-assisted extraction technique not only increased the extraction yield, but also greatly shorten the extraction time.

2. The possible extraction mechanisms of the microwave-assisted extraction and the traditional Soxhlet extraction were derived and confirmed via scanning electron micrographs. Microwave radiation plays a vital role in the rupture of the vegetal cell walls, which led to the improvement in the extraction efficiency. Furthermore, the results of the FTIR analysis showed that the functional groups of the flavonoids extracted via microwave-assisted extraction and traditional Soxhlet extraction were fundamentally identical.

3. The antioxidant activities in vitro of flavonoids from Phyllostachys heterocycla leaves were evaluated via DPPH and ABTS radical scavenging assays. The results indicated that the flavonoids from Phyllostachys heterocycla leaves had higher antioxidant 
activities in vitro. In addition, this confirmed that Phyllostachys heterocycla leaves could be a new natural source for developing antioxidants in the clinical industry.

4. The application of microwave-assisted extraction is a potential strategy for improving the yield of flavonoids from Phyllostachys heterocycla leaves. This research could provide a theoretical reference for the development of novel microwave set-ups for possible commercial production of various flavonoids and promote the exploitation of new extraction method based on microwave, such as dynamic microwave extraction.

\section{ACKNOWLEDGMENTS}

This work was financially supported by the National Natural Science Foundation of China (No. 51704292 and 51974311), the National Key Research and Development Program of China (No. 2019YFC1904302), and the Open Sharing Fund for the Large-scale Instruments and Equipment of China University of Mining and Technology.

\section{REFERENCES CITED}

Alara, O. R., Abdurahman, N. H., and Mudalip, S. K. A. (2019). “Optimizing microwave-assisted extraction conditions to obtain phenolic-rich extract from Chromolaena odorata leaves," Chemical Engineering \& Technology 42(9), 17331740. DOI: $10.1002 /$ ceat.201800462

Alirezalu, K., Pateiro, M., Yaghoubi, M., Alirezalu, A., Peighambardoust, S. H., and Lorenzo, J. M. (2020). "Phytochemical constituents, advanced extraction technologies and techno-functional properties of selected Mediterranean plants for use in meat products. A comprehensive review," Trends in Food Science \& Technology 100, 292-306. DOI: 10.1016/j.tifs.2020.04.010

Bouras, M., Chadni, M., Barba, F. J., Grimi, N., Bals, O., and Vorobiev, E. (2015). "Optimization of microwave-assisted extraction of polyphenols from Quercus bark," Industrial Crops and Products 77, 590-601. DOI: 10.1016/j.indcrop.2015.09.018

Butsat, S., and Siriamornpun, S. (2016). "Effect of solvent types and extraction times on phenolic and flavonoid contents and antioxidant activity in leaves extracts of Amomum chinense C," International Food Research Journal 23(1), 180-187.

Carbone, K., Macchioni, V., Petrella, G., and Cicero, D. O. (2020). "Exploring the potential of microwaves and ultrasounds in the green extraction of bioactive compounds from Humulus lupulus for the food and pharmaceutical industry," Industrial Crops and Products 156, 1-14. DOI: 10.1016/j.indcrop.2020.112888

Cardoso-Ugarte, G. A., Sosa-Morales, M. E., Ballard, T., Liceaga, A., and MartinGonzalez, M. F. S. (2014). "Microwave-assisted extraction of betalains from red beet (Beta vulgaris)," LWT - Food Science and Technology 59(1), 276-282. DOI: 10.1016/j.lwt.2014.05.025

Chaves, J. O., de Souza, M. C., da Silva, L. C., Lachos-Perez, D., Torres-Mayanga, P. C., Machado, A. P. d. F., Forster-Carneiro, T., Vazquez-Espinosa, M., Gonzalez-dePeredo, A. V., Barbero, G. F., et al. (2020). "Extraction of flavonoids from natural sources using modern techniques," Frontiers in Chemistry 8, 1-25. DOI:

10.3389/fchem.2020.507887 
Chen, X.-Q., Li, Z.-H., Liu, L.-L., Wang, H., Yang, S.-H., Zhang, J.-S., and Zhang, Y. (2021). "Green extraction using deep eutectic solvents and antioxidant activities of flavonoids from two fruits of Rubia species," LWT - Food Science and Technology 148, 1-9. DOI: 10.1016/j.lwt.2021.111708

Fang, J., Gao, S., Islam, R., Teramoto, Y., and Maeda, H. (2020). "Extracts of Phellinus linteus, bamboo (Sasa senanensis) leaf and chaga mushroom (Inonotus obliquus) exhibit antitumor activity through activating innate immunity," Nutrients 12(8), 1-12. DOI: $10.3390 /$ nu 12082279

Gao, Q., Shi, Y., Liao, M., Xiao, J., Li, X., Zhou, L., Liu, C., Liu, P., and Cao, H. (2019). "Laboratory and field evaluation of the aphidicidal activity of moso bamboo (Phyllostachys pubescens) leaf extract and identification of the active components," Pest Management Science 75(12), 3167-3174. DOI: 10.1002/ps.5434

Gao, S., Han, W., and Deng, X. (2004). "Study of the mechanism of microwave-assisted extraction of Mahonia bealei (Foft.) leaves and Chrysanthemum morifolium (Ramat.) petals," Flavour and Fragrance Journal 19(3), 244-250. DOI: 10.1002/ffj.1296

Ge, Q., Li, H., Wu, P., Sha, R., Xiao, Z., Dai, J., and Mao, J. (2020). "Investigation of physicochemical properties and antioxidant activity of ultrafine bamboo leaves powder prepared by ball milling," Journal of Food Processing and Preservation 44(7), 1-9. DOI: 10.1111/jfpp.14506

Geetha, N., Harini, K., Joseph, M., Sangeetha, R., and Venkatachalam, P. (2019). "A comparison of microwave-assisted medicinal plant extractions for detection of their phytocompounds through qualitative phytochemical and FTIR analyses," Iranian Journal of Science and Technology, Transactions A: Science 43(2), 397-407. DOI: 10.1007/s40995-017-0424-5

Ghafari, S., Aziz, H. A., Isa, M. H., and Zinatizadeh, A. A. (2009). “Application of response surface methodology (RSM) to optimize coagulation-flocculation treatment of leachate using poly-aluminum chloride (PAC) and alum," Journal of Hazardous Materials 163(2-3), 650-656. DOI: 10.1016/j.jhazmat.2008.07.090

Ghaffar, N., Javad, S., Farrukh, M. A., Akhtar, I., and Tariq, A. (2020). “Optimization of parameters for microwave-assisted extraction of phenolics and flavonoids from Euphorbia hirta by response surface methodology," Phyton 60(1), 1-9. DOI: 10.12905/0380.phyton60-2020-0001

Gong, J., Xia, D., Huang, J., Ge, Q., Mao, J., Liu, S., and Zhang, Y. (2015). “Functional components of bamboo shavings and bamboo leaf extracts and their antioxidant activities in vitro," Journal of Medicinal Food 18(4), 453-459. DOI: 10.1089/jmf.2014.3189

Hamad, M. N. (2012). "Isolation of rutin from Ruta graveolens (Rutaceae) cultivated in Iraq by precipitation and fractional solubilization," Pharmacie Globale International Journal of Comprehensive Pharmacy 3(4), 1-3.

He, M., Wang, J., Qin, H., Shui, Z., Zhu, Q., Wu, B., Tan, F., Pan, K., Hu, Q., Dai, L., et al. (2014). "Bamboo: A new source of carbohydrate for biorefinery," Carbohydrate Polymers 111, 645-654. DOI: 10.1016/j.carbpol.2014.05.025

He, Q., Li, Y., Zhang, P., Zhang, A., and Wu, H. (2016). 'Optimization of microwaveassisted extraction of flavonoids and phenolics from Celery (Apium graveolens L.) leaves by response surface methodology," Czech Journal of Food Sciences 34(4), 341-349. DOI: 10.17221/266/2015-CJFS

Ho, T. C., and Chun, B.-S. (2019). "Extraction of bioactive compounds from Pseuderanthemum palatiferum (Nees) Radlk. using subcritical water and conventional 
solvents: A comparison study," Journal of Food Science 84(5), 1201-1207. DOI: 10.1111/1750-3841.14501

Hu, J., Wang, J., Li, S., Yang, B., Gong, M., Li, X., Zhang, L., and Tian, J. (2016). "Phytochemical compositions, antioxidant and antimicrobial activities analysis of extracts from Vaccinium bracteatum Thunb. leaves," Journal of Applied Botany and Food Quality 89, 150-155. DOI: 10.5073/JABFQ.2016.089.018

Kaanin-Boudraa, G., Brahmi, F., Wrona, M., Nerín, C., Moudache, M., Mouhoubi, K., Madani, K., and Makhlouf-Boulekbache, L. (2021). "Response surface methodology and UPLC-QTOF-MSE analysis of phenolic compounds from grapefruit (Citrus $x$ paradisi) by-products as novel ingredients for new antioxidant packaging," $L W T$ Food Science and Technology 151(2), 1-11. DOI: 10.1016/j.lwt.2021.112158.

Kaderides, K., Papaoikonomou, L., Serafim, M., and Goula, A. M. (2019). "Microwaveassisted extraction of phenolics from pomegranate peels: Optimization, kinetics, and comparison with ultrasounds extraction," Chemical Engineering \& Processing Process Intensification 137, 1-11. DOI: 10.1016/j.cep.2019.01.006

Karpagasundari, C., and Kulothungan, S. (2014). "Analysis of bioactive compounds in Physalisminima leaves using GC MS, HPLC, UV-VIS and FTIR techniques," Journal of Pharmacognosy and Phytochemistry 3(4), 196-201.

Lee, C. S., Binner, E., Winkworth-Smith, C., John, R., Gomes, R., and Robinson, J. (2016). "Enhancing natural product extraction and mass transfer using selective microwave heating," Chemical Engineering Science 149, 97-103. DOI: 10.1016/j.ces.2016.04.031

Li, X., Tao, W., Xun, H., Yao, X., Wang, J., Sun, J., Yue, Y., and Tang, F. (2021). "Simultaneous determination of flavonoids from bamboo leaf extracts using liquid chromatography-tandem mass spectrometry," Revista Brasileira de Farmacognosia 31, 347-352. DOI: 10.1007/s43450-021-00158-1

Li, Y., Han, F., and Shi, Y. (2013). "1178 - Correlation study of apoptosis-related genes bcl-2, bax and ptsd in rat medial prefrontal cortex neuronal apoptosis," European Psychiatry 28(S1), 1-1. DOI: 10.1016/S0924-9338(13)76264-3

Liu, Z., Wang, S., Li, Q., Dong, F., Li, H., Wang, Z., Dai, L., Wei, X., and Zhang, J. (2021). "Diagnostic product ions-based chemical characterization and antioxidative activity evaluation of solid fermentation for Astragali radix produced by Paecilomyces cicadae," Arabian Journal of Chemistry 14(1), 1-21. DOI: 10.1016/j.arabjc.2020.11.014

Lu, J., Zhou, C., Rong, O., Xu, Y., Zhou, B., and Li, Z. (2013). “Optimization of microwave-assisted extraction of flavonoids from Cryptotaenia japonica Hassk using response surface methodology," Advance Journal of Food Science and Technology 5(3), 310-317. DOI: 10.19026/ajfst.5.3262

Ma, N.-H., Guo, J., Chen, S.-H. X., Yuan, X.-R., Zhang, T., and Ding, Y. (2020). "Antioxidant and compositional HPLC analysis of three common bamboo leaves," Molecules 25(2), 1-14. DOI: 10.3390/molecules25020409

Ma, W., Lu, Y., Dai, X., Liu, R., Hu, R., and Pan, Y. (2009). "Determination of antitumor constitute mollugin from traditional Chinese medicine Rubia cordifolia: Comparative study of classical and microwave extraction techniques," Separation Science and Technology 44(4), 995-1006. DOI: 10.1080/01496390802691265

Meenakshi, S., Gnanambigai, D. M., Mozhi, S. T., Arumugam, M., and Balasubramanian, T. (2009). "Total flavonoid and in vitro antioxidant activity of two seaweeds of Rameshwaram Coast," Global Journal of Pharmacology 3(2), 59-62. 
Mišan, A., Nađpal, J., Stupar, A., Pojić, M., Mandić, A., Verpoorte, R., and Choi, Y. H. (2020). "The perspectives of natural deep eutectic solvents in agri-food sector," Critical Reviews in Food Science and Nutrition 60(15), 2564-2592. DOI: 10.1080/10408398.2019.1650717

Odabaş, H. I., and Koca, I. (2021). "Simultaneous separation and preliminary purification of anthocyanins from Rosa pimpinellifolia L. fruits by microwave-assisted aqueous two-phase extraction," Food and Bioproducts Processing 125, 170-180. DOI: 10.1016/j.fbp.2020.11.007

Orsat, V., and Routray, W. 2017. "Chapter 8 - Microwave-assisted extraction of flavonoids," in: Water Extraction of Bioactive Compounds from Plants to Drug Development, First Ed., H. D. Gonzalez and M. J. G. Munoz (eds.), Elsevier, pp. 221244. DOI: 10.1016/B978-0-12-809380-1.00008-5

Patle, T. K., Shrivas, K., Kurrey, R., Upadhyay, S., Jangde, R., and Chauhan, R. (2020). "Phytochemical screening and determination of phenolics and flavonoids in Dillenia pentagyna using UV-vis and FTIR spectroscopy," Spectrochimica Acta Part A: Molecular and Biomolecular Spectroscopy 242, 1-10. DOI: 10.1016/j.saa.2020.118717

Petrotos, K., Giavasis, I., Gerasopoulos, K., Mitsagga, C., Papaioannou, C., and Gkoutsidis, P. (2021). "Optimization of vacuum-microwave-assisted extraction of natural polyphenols and flavonoids from raw solid waste of the orange juice producing industry at industrial scale," Molecules 26(1), 1-27. DOI: 10.3390/molecules26010246

Proestos, C., and Komaitis, M. (2008). "Application of microwave-assisted extraction to the fast extraction of plant phenolic compounds," LWT - Food Science and Technology 41(4), 652-659. DOI: 10.1016/j.lwt.2007.04.013

Routray, W., and Orsat, V. (2012). "Microwave-assisted extraction of flavonoids: A review," Food and Bioprocess Technology 5(2), 409-424. DOI: 10.1007/s11947-0110573-Z

Routray, W., and Orsat, V. (2014). "MAE of phenolic compounds from blueberry leaves and comparison with other extraction methods," Industrial Crops and Products 58, 36-45. DOI: 10.1016/j.indcrop.2014.03.038

Shamsuddin, T., Alam, M. S., Junaid, M., Akter, R., Hosen, S. M. Z., Ferdousy, S., and Mouri, N. J. (2021). "Adhatoda vasica (Nees.): A review on its botany, traditional uses, phytochemistry, pharmacological activities and toxicity," Mini-Reviews in Medicinal Chemistry 21(14), 1925-1964. DOI: $10.2174 / 1389557521666210226152238$

Su, Y., Dong, H., Li, M., Lai, C., Huang, C., and Yong, Q. (2019). "Isolation of the flavonoid from bamboo residues and its application as metal ion sensor in vitro," Polymers 11(9), 1-16. DOI: 10.3390/polym11091377

Tanongkankit, Y., Sablani, S. S., Chiewchan, N., and Devahastin, S. (2013). "Microwave-assisted extraction of sulforaphane from white cabbages: Effects of extraction condition, solvent and sample pretreatment," Journal of Food Engineering 117(1), 151-157. DOI: 10.1016/j.jfoodeng.2013.02.011

Tao, C., Wang, Y., Zhang, X., Li, L., Wu, Y., Han, X., Jiang, X., and Lv, Z. (2019). "Mechanism of action of essential oils extracted from bamboo (Phyllostachys heterocycla $\mathrm{cv}$. pubescens) leaves: Chemical composition and antimicrobial activity against four food-related microorganisms," BioResources 14(1), 1419-1434. DOI: 10.15376/biores.14.1.1419-1434 
Vinatoru, M., Mason, T., and Calinescu, I. (2017). "Ultrasonically assisted extraction (UAE) and microwave-assisted extraction (MAE) of functional compounds from plant materials," TrAC Trends in Analytical Chemistry 97, 159-178. DOI: 10.1016/j.trac.2017.09.002

Wang, C., Li, Z., Li, F., Chen, M., Wang, Y., Li, Y., and He, D. (2012). “Optimization of microwave-assisted extraction conditions for total flavonoids in Toona sinensis leaves using response surface methodology," International Journal of Food Engineering 8(4), 295-300. DOI: 10.1515/1556-3758.1933

Xia, G.-H., Li, X.-H., and Jiang, Y. (2021). "Deep eutectic solvents as green media for flavonoids extraction from the rhizomes of Polygonatum odoratum," Alexandria Engineering Journal 60(2), 1991-2000. DOI: 10.1016/j.aej.2020.12.008

Yadav, N., Sharma, S., Joys, J.S., and Kumar, S. (2020). "Microwave-assisted extraction of bioactive compounds: A brief review," Journal of the Indian Chemical Society 97(OctoberA), 1751-1756.

Yuan, T., Guo, X.-F., Shao, S.-Y., An, R.-M., Wang, J., and Sun, J. (2020). "Characterization and identification of flavonoids from Bambusa chungii leaves extract by UPLC-ESI-Q-TOF-MS/MS," Acta Chromatographica 33(3), 281-294. DOI: $10.1556 / 1326.2020 .00777$

Yuan, W., Fan, W., Mu, Y., Meng, D., Yan, Z., Li, Y., and Lv, Z. (2021). "Baking intervention for the interaction behaviors between bamboo (Phyllostachys heterocycla) leaves flavonoids and gliadin," Industrial Crops and Products 164, 1-10. DOI: 10.1016/j.indcrop.2021.113385

Zhang, H.-F., Yang, X.-H., and Wang, Y. (2011). "Microwave-assisted extraction of secondary metabolites from plants: Current status and future directions," Trends in Food Science \& Technology 22(12), 672-688. DOI: 10.1016/j.tifs.2011.07.003

Zhong, L., Zhang, Y., Chi, R., and Yu, J. (2016). "Optimization of microwave-assisted ethanol reflux extraction process of flavonoids and saponins simultaneously from Radix Astragali using response surface methodology," Food Science and Technology Research 22(6), 759-770. DOI: 10.3136/fstr.22.759

Zhu, H., Wang, Y., Liu, Y., Xia, Y., and Tang, T. (2010). "Analysis of flavonoids in Portulaca oleracea L. by UV-Vis spectrophotometry with comparative study on different extraction technologies," Food Analytical Methods 3(2), 90-97. DOI: 10.1007/s12161-009-9091-2

Article submitted: September 3, 2021; Peer review completed: October 9, 2021; Revised version received and accepted: October 11, 2021; Published: October 17, 2021.

DOI: 10.15376/biores.16.4.8060-8081 